\title{
Remote Sensing Systems At The Rocket's Payload Test
}

\author{
C.G.I. Partha ${ }^{1}$, I.N. Budiastra ${ }^{2}$, A.A.N. Amrita $^{3}$ and I.M. Suartika ${ }^{4}$ \\ ${ }^{1,2,3,4}$ Electrical Engineering Department, Faculty of Engineering \\ Udayana University (UNUD) \\ Badung, Bali, Indonesia \\ cokindra@unud.ac.id
}

\begin{abstract}
Aviation technology and space is one of the leading technology for developed countries, especially in the form of rocket technology and payload. Countries that are capable of mastering these technologies will be respected by countries all over the world. Indonesia as the island nation and the State's large and extensive maritime already should have independence in the mastery of the technology of the rocket and payload. Therefore, continuous efforts are required to achieve independence, including through enhancing aviation technology and space technology, particularly at early stages the rocket and payload.

Remote Sensing Systems At the rocket's Payload was Test remote monitoring system image capture and the attitude of the launch payload through the computer screen (display) continuously (real-time) data obtained from sensors that are mounted on the rocket's payload. 3D point $(\mathrm{x}, \mathrm{y}, \mathrm{z})$ must be expressed as a graph visualization perspective drawings of rockets with the appropriate direction. The radar conducted computer GS (Ground Segment) or Ground Control Station (GCS). The result of the attitude of the Rocket Test launch Payloads have been able to do the communication data transmission of images and data for 3D $(\mathrm{x}, \mathrm{y}$, and $\mathrm{z})$ in real-time to the Ground segment. Wireless communication uses radio telemetry frequency $433 \mathrm{MHz}$, power of 100 $\mathrm{mW}$, the distance range obtained in this study a maximum of 1000 meter in conditions in the air and without obstruction.
\end{abstract}

Index Terms — Graphic Monitoring, Remote Sensing Systems, Rocket, Sensors.

\section{INTRODUCTION}

Aviation and space technology is one of the leading technology for developed countries, especially in the form of rocket technology and payload. Countries that are capable of mastering these technologies will be respected by countries all over the world. Indonesia as the island nation and the State's large and extensive maritime already should have independence in mastering rocket technology and charge, therefore the required continuous efforts to achieve independence, only through the efforts of cultivate the sense of love of aviation technology and space technology, particularly at early stages of the rocket and payload.

In its development of a rocket payload forward the results of this architecture can be a forerunner of the birth of Indonesia satellite and rocket launcher works of Indonesia nation independently. While the rockets EDF mainly its control technology, a more sophisticated scale again could be developed into a forerunner of Satellite rocket launcher. In addition, KOMURINDO can also increase the sense of unity and nationalism, unity on the importance of maintaining the dignity and sovereignty of aerospace through mastery of flight technology and space exploration, particularly the rocket and payload. In addition it can also shorten the distance difference mastery of science and technology and space flight and can expand its spread among tertiary institutions across Indonesia.

\section{METHODS}

\section{A. Stages and data analysis}

In this research, there are several stages that are done from the beginning of the study until the end of the study. The first stage is checked or check out the equipment used, the tools used must comply with the existing problems, namely can make a rocket payload Graphic Monitoring Test Rocket 
Launch Payload Attitude to find out directions from the plan of direction from the payload .

Other support tools also prepared i.e. by installing some software such as the Arduino IDE and application of ground station. The second piece of software that will be used to create programs that will run on sensor Accelerometer ADXL345, henceforth will be visualized in the form of graphs.

\section{The design of sensor accelerometer ADXL345}

In the design of the hardware, will be made a series of vibration sensors that connect between the ADXL345 and Arduino and a USB cable that will connect the Arduino with the computer, as shown in Figure 1.

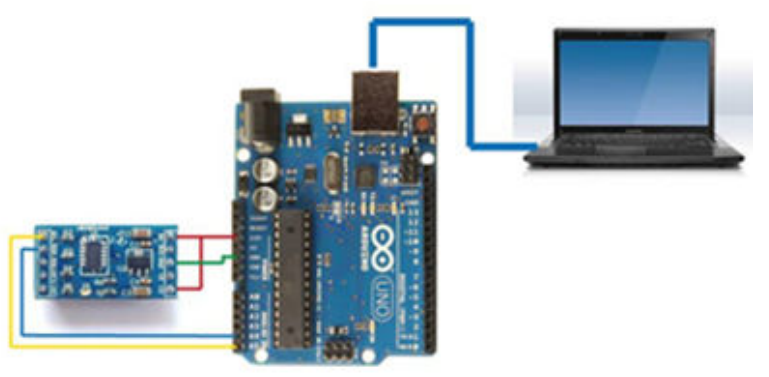

Fig.1 Design of accelerometer ADXL with Arduino and computer

Accelerometer ADXL345 and Arduino must be connected at some pins. This pin must be connected between the accelerometer ADXL345 and Arduino:

1. Pin CS (chip select) and a $5 \mathrm{~V}$ pin on the Accelerometer ADXL345 connected with pins on an Arduino UNO $3 \mathrm{v} 3$. This pin serves as a place of power supply of both.

2. Ground (GND) Pin on the Accelerometer ADXL345 connected with GND pin on the Arduino. This pin serves as a place to ground.

3. Pin (SDA) on Accelerometer ADXL345 connected with A4 pin on the Arduino. This pin serves as the serial input data on $\mathrm{I} 2 \mathrm{C}$ communication.

4. Pin (SCL) on Accelerometer ADXL345 connected with pin A5 on the Arduino UNO. SCL pin on the accelerometer ADXL345 here serves as a clock on the I2C data communications.

5. USB cable will be connected to the Notebook via the USB port found on the Arduino and accelerometer and the microcontroller automatically will be active once connected on the notebook marked with RX TX and lights turned on.

\section{Design of application Program Arduino IDE}

The Arduino IDE is useful of the Arduino software as the compiler for the Arduino microcontroller type using $\mathrm{C}$ language for programming. On the Arduino IDE software for this program will be created that contains instructions that will be executed by the Arduino microcontroller. Program that will be created will arrange communication between Arduino with Accelerometer ADXL345 using the I2C communication as well as setting work on the accelerometer ADXL345. In a program that made this microcontroller will only read the data axis acceleration $\mathrm{x}, \mathrm{y}$ and $\mathrm{z}$ from the measurements performed by the accelerometer ADXL345 and further the acceleration results data will be sent to computer. This is done by way of making the microcontroller just read the output to address acceleration axes $\mathrm{x}, \mathrm{y}$ and $\mathrm{z}$ on the accelerometer ADXL345. The first step to do initialization of accelerometer ADXL345 and instruction-instruction used in the Arduino microcontroller.

\section{Data communications without wires}

The design of data communication with no wired or wireless was conducted after the program can communicate with the arduino and accelerometer response has been received in its entirety through the USB cable. The design is shown in Figure 2.

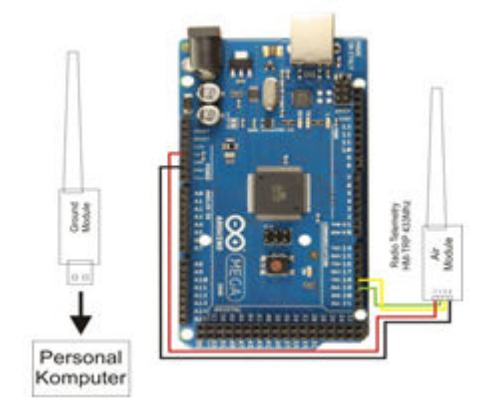

Fig. 2. The Arduino with radio communication

The selected communication radio is a radio that has a frequency that is legal and free to use. In this frequency planning is used $433 \mathrm{MHz}$, with a maximum transmitter power of $100 \mathrm{~mW}$.

\section{B. Data analysis}

In the operation of the rocket's payload uses the accelerometer ADXL345, common error error sending data for axes $x, y$ and $z$. ADXL345 Sensor will get data acceleration be the change of layout and positioning of the payload of the axis $\mathrm{x}, \mathrm{y}$ and $\mathrm{z}$. Then the data taken will be sent to the Arduino using the communication Inter Integrated Circuit (I2C). In the Arduino microcontroller is using software inside that compile using Arduino IDE 1.0.6 compiler so the data shown axes $\mathrm{x}, \mathrm{y}$ and $\mathrm{z}$. After the data processed on the Arduino UNO R3 and produced data on axes $\mathrm{x}, \mathrm{y}$ and $\mathrm{z}$, then the data is sent to computer by using the radio TX/RX $433 \mathrm{MHz}$ for further processed and displayed on the computer through the application of Visual Basic in the form of graphs and numeric data. The data obtained are then processed using the standard deviation equation for knowing the value of the frequency limit will be the reference values for indicators of error. 


\section{RESULTS}

\section{A. Design of the Rocket's Payload}

Payload by using the accelerometer and gyroscope sensor which has been designed using software sketch up pro can be seen in Figure 3. The specifications of the rocket's payload shown in table 1 . This specification refers to the basic rules of the dimensions of the payload that is issued by KOMURINDO/Competition Payloads In Indonesia.

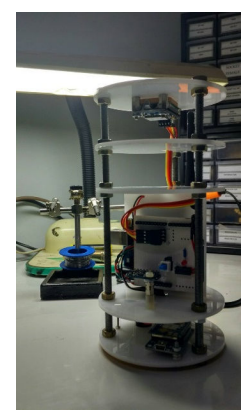

Fig. 3. Payload

TABLE 1 . SPECIFICATIONS OF THE ROCKET'S PAYLOAD

\begin{tabular}{cll}
\hline No. & Specifications & Payload \\
\hline 1 & High & $10 \mathrm{~cm}$ \\
2 & Width (Surface) & $20 \mathrm{~cm}$ \\
3 & The Diameter Of The Base & $10 \mathrm{~cm}$ \\
4 & The weight of the & $800 \mathrm{gram}$ \\
5 & Battery & $11.1 \mathrm{~V}_{\mathrm{DC}} 2.2 \mathrm{~A}$ \\
6 & Microcontroller & Arduino Mega \\
7 & Working Voltage & $5 \mathrm{~V}$ \\
\hline
\end{tabular}

\section{B. Test Interface GCS when shooting}

On the Ground Segment also contains functions for ordering the shooting through a camera in the payload. At the time of the command button to take a picture is clicked then GCS will send serial commands to the system so that the data payload sensors while stopped and carried out the taking and delivery of image data in the form which is then treated hexadecimal in GCS and displayed in the form of pictures. In Figure 4 looks at testing the rocket's payload image data retrieval when done testing.

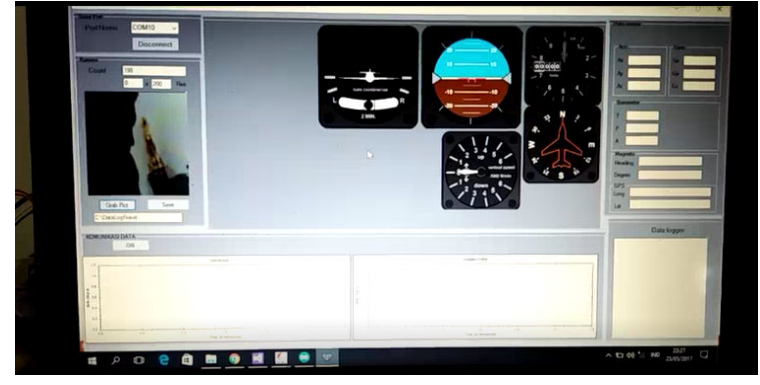

Fig. 4. The Payload test results when shooting

\section{The design of the antenna Tracker}

We uses the antenna design of the existing tracker as a reference. But the design also matched with the shape and size of the components used. The design will be divided into 2 parts, namely part that rotates and the part that does not spin. On the part not spinning will be made a-shaped box that can accommodate several components like the Arduino Mega, GPS sensor, Xbee, receivers, sensors, compass HMC5883L, UBEC, battery and servo.

Antenna tracker designed using $900 \mathrm{MHz} 60 \mathrm{dbi}$ yagi. On the system of the antenna using the arduino uno, HMC5883L, compass sensor ublox neo 6 and servo motor. The antenna will get the value of the Longitude and Latitude of the GPS on payload sent from ground segment. Then the latitude and longitude values will be compared to the values obtained by the GPS antenna system. And the servo on the antenna will rotate the antenna direction accordance with the comparison data. In Figure 5 indicated the form of realization of the antenna Tracker

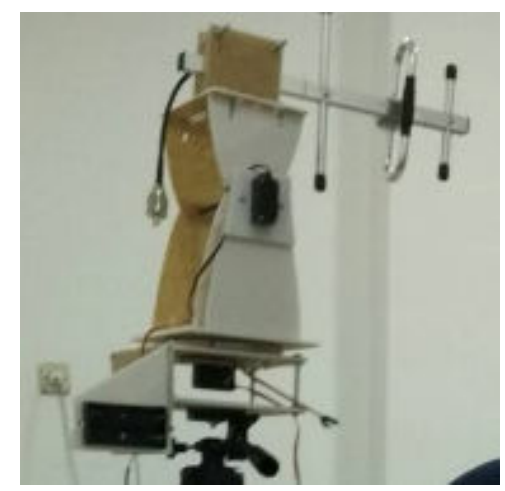

Fig. 5. Realization of the antenna Tracker

\section{Test launch of a rocket Payload}

To perform the test Graphics Monitoring research Rocket Launch Test Payload Attitude, then thoroughly done by carrying and fly a payload. In this design the payload has a weight of no more than 1000 grams with a diameter of 10 $\mathrm{cm}$ and a height of $20 \mathrm{~cm}$. Prior to launch, testing is done on the ground to find out the function of radio telemetry payload and spacecraft telemetry radio the Launcher. In Figure 6 radio telemetry indicated testing between payload 
and spacecraft launchers. While the process of launching the rocket test charge is shown in Figure 6. In the process of this launch was successful and the data from the payload can be send to the ground control station. Accelerometer data delivery that was in the payload sent in real time starting from a distance of 0 up to 500 meters. After passing over a distance of 100 meters, deliveries disrupted and disjointed. Radio telemetry data from the specifications used are of $100 \mathrm{~mW}$, with a range as far as 1000 meters.

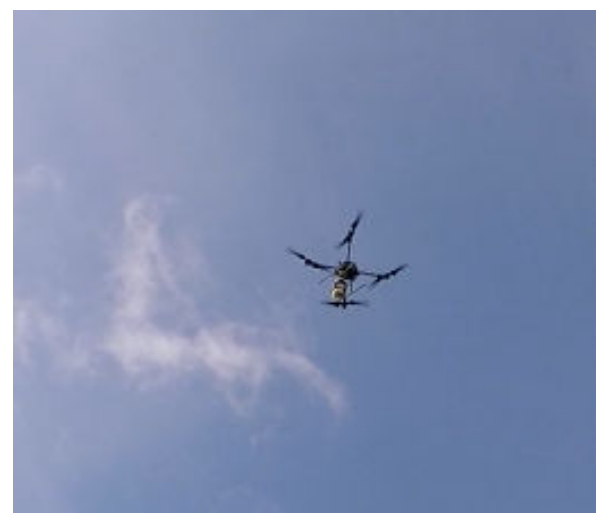

Fig. 6. The launch of the rocket's Payload

\section{CONCLUSION}

1. Payload is a charge by applying high-tech monitoring technology as having boundaries in accordance with sensors is used.

2. Payload rocket test can already communicate with the Ground control system and send the image data, speed, acceleration of the launch as well as the position of the charge.

3. A vehicle without the crew being made could've controlled the position using radio control for testing rocket payloads.

\section{ACKNOWLEDGMENT}

On this occasion, the researchers are very grateful to Research and Community Service of Udayana University and Ministry of Research, Technology and Higher Education with the contribution conducting research competitive grants scheme, so that the research could be conducted

\section{REFERENCES}

[1] Anonymous. (t. yrs.). Analog Device. Taken back from ADXL345 Data Sheets: http://www.analog.com/static/imported-files/ data sheets/ADXL345.pdf

[2] Anonymous. (t. yrs.) the Arduino. Taken back from the Arduino IDE: http://www.Arduino.cc/downloads/ArduinoIDE

[3] Anonymous. (t. yrs.) Atmel. Taken back from 328 Datasheet: ATMega Microcontroller www.atmel.com

[4] Arduino. (t. yrs.) Taken back from www. Arduino. cc: http://www.Arduino.cc/learn/arduino
[5] Hendry. 2009. Berbagai Aplikasi Database Dengan Visual Basic 6.0. Jakarta : Elexmedia Komputindo.

[6] Kuhnel, Claus. 2001. BASCOM Programming of Microcontrollers with Easy.USA: Universal Publishers 